\title{
UŚCIŚLONY MODEL IMPERFEKCYJNYCH OBCIĄŻEŃ PLATWI I STĘŻEŃ
}

\begin{abstract}
Przedstawiono uściślone modele identyfikacji obciążeń imperfekcyjnych stężanych kratownic swobodnie podpartych. Wyznaczono je uwzględniając rzeczywisty paraboliczny rozkład sił w stężanym elemencie oraz skręcenie płaszczyzny głównej kratownicy. Podano zależności analityczne służące do obliczania obciążeń imperfekcyjnych w analizie wytężenia płatwi i stężeń. Przeprowadzono dyskusję otrzymanych wyników.
\end{abstract}

Słowa kluczowe: obciążenia imperfekcyjne, kratownica, skręcenie kratownicy, płatew, stężenie

\section{Wprowadzenie}

Według [3] w analizie stężeń zapewniających stateczność boczną stabilizowanemu elementowi stosuje się model wstępnie łukowo wygiętego pręta. Jest on ściskany stałą na jego długości siłą $N_{1}(x)=$ const. Jako bezpieczne przyjmuję się jej wartość równą maksymalnej sile w elemencie $N_{1}(x)=N_{E d}$. Zastępcze obciążenie imperfekcyjne pręta jest równomiernie rozłożone $q_{d 1}(x)=q_{d 1}=$ const.

Założenie $N_{1}(x)=$ const nie jest zgodne z rzeczywistym nierównomiernym rozkładem siły ściskającej na długości stabilizowanego pasa dźwigara dachowego. W przypadku np. dźwigarów swobodnie podpartych, siła w ściskanym pasie $\mathrm{N}_{2}(x)$ ma rozkład paraboliczny, a więc jest zmienna na jego długości. Dla takiej siły ściskającej, rozkład obciążenia imperfekcyjnego $q_{d 2}(x)$ jest również zmienny na długości pasa (jest nierównomierny i znakozmienny). Analizując rozkład sił w łuku w [2], numerycznie obliczono obciążenie imperfekcyjne $q_{d 2}(x)$ i wykazano, że różni się ono zasadniczo od obciążenia $q_{d 1} \mathrm{wg}$ [3].

$\mathrm{W}$ pracy podano uściślone, uogólnione modele obliczania imperfekcyjnych obciążeń swobodnie podpartych kratownic dachowych oraz oceny wytężenia

\footnotetext{
${ }^{1}$ Autor do korespondencji/corresponding author: Antoni Biegus, Politechnika Wrocławska, Wydział Budownictwa Lądowego i Wodnego, Wybrzeże Wyspiańskiego 27, 50-370 Wrocław, tel. 71 3203766, antoni.biegus@pwr.edu.pl

${ }^{2}$ Dariusz Czepiżak, Politechnika Wrocławska, Wydział Budownictwa Lądowego i Wodnego, Wybrzeże Wyspiańskiego 27, 50-370 Wrocław, tel. 71 3202367, dariusz.czepizak@pwr.edu.pl
} 
płatwi i stężeń. Uwzględniono w nich paraboliczny rozkład sił ściskających $\mathrm{N}_{2}(x)$ w usztywnianym elemencie. Zaproponowano zależności analityczne służące do wyznaczania obciążeń imperfekcyjnych, które są zdecydowanie większe od obliczonych wg [3]. Przeprowadzono dyskusję otrzymanych wyników.

\section{Oddziaływanie imperfekcyjne elementu ściskanego stałą silą}

Według [3] sumaryczne obciążenie imperfekcyjne $q_{d 1}$ od wygięcia o strzałce $e_{0}=L / 500$ (rys. 1a) stężanych $\mathrm{m}$ elementów jest równomiernie rozłożone (rys. 1c) i oblicza się je ze wzoru:

$$
q_{d 1, m}=\sum_{j=1}^{m} 8 N_{E d, j} \frac{e+\delta_{q 1, w}}{L^{2}}
$$

gdzie: $e$ - imperfekcja sumaryczna stężanych elementów, która wynosi:

$$
e=(L / 500) \sqrt{0,5\left(1+m^{-1}\right)}
$$

W (1) i (2) przyjęto oznaczenia wg [3].

a)
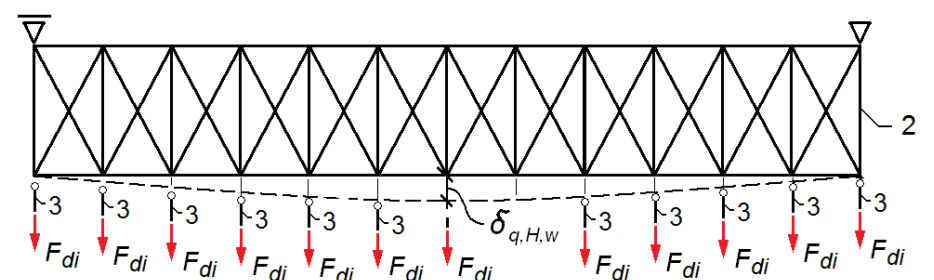

$F_{d i} F_{d i} F_{d i} F_{d i} F_{d i} F_{d i} F_{d i}$

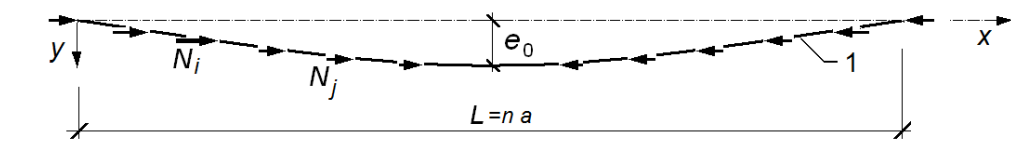

b)

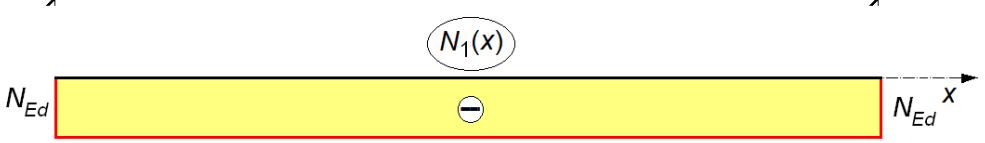

c)

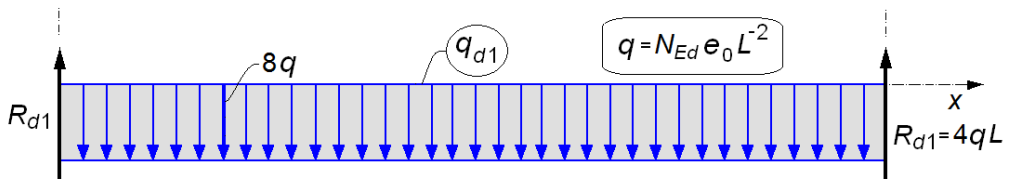

Rys. 1. Model obliczeniowy stężenia wg [3]: a) schemat stężenia i stężanego elementu, b) rozkład siły w elemencie, c) obciążenie imperfekcyjne $q_{d 1}$; 1 - stężany element, 2 - stężenie, 3 - płatew

Fig. 1. Calculation model of bracing system according [3]: a) scheme of a bracing system and the restrained member, b) distribution of force in the member, c) loadings $q_{d 1}$ from imperfections; 1 - restrained member, 2 - bracing system, 3 - purlin 
Obciążenie $q_{d 1}$ (rys. 1c) wyznaczono zakładając, że stężany element jest ściskany stałą na swej długości siłą $N_{1}(x)=N_{E d}=$ const (rys. 1b).

Imperfekcyjne siły podłużne $F_{d 1, m}$ W płatwiach pośrednich od $m$ stężanych elementów oblicza się ze wzoru:

$$
F_{d 1, m}=8 \sum_{j=1}^{m} N_{E d, j} a \frac{e+\delta_{q 1, w}}{L^{2}}
$$

gdzie: $a$ - rozstaw płatwi.

Największe imperfekcyjne siły podłużne występują w płatwiach okapowych $R_{d 1, m}=F_{d 1, m}(0)=F_{d 1, m}(L)$ i wynoszą:

$$
R_{d 1, m}=F_{d 1, m}(0)=F_{d 1, m}(L)=4 \sum_{j=1}^{m} N_{E d, j} \frac{e+\delta_{q 1, w}}{L^{2}}(L-a)
$$

\section{Oddziaływanie imperfekcyjne elementu ściskanego siłą para- bolicznie zmienną na jego długości}

Rozpatrzono obciążenie imperfekcyjne swobodnie podpartego dźwigara dachowego, który jest usztywniany w płaszczyźnie połaci dachu stężeniem poprzecznym (rys. 1a). Rozkład sił ściskających $N_{2}(x)$ na długości stężanego pasa górnego dźwigara dachowego jest paraboliczny (rys. 2a) i opisuje go zależność:

$$
N(x)=4 N_{E d} \frac{x}{L^{2}}(L-x)
$$

Przyjęto wstępne paraboliczne (wg [3]) wygięcie elementu (pasa ściskanego dźwigara) w płaszczyźnie połaci dachu (rys. 1b), które oblicza się ze wzoru:

$$
y(x)=4 e_{0} \frac{x}{L^{2}}(L-x)
$$

Korzystając z równania różniczkowego linii ugięcia wyznaczono [1] jego zastępcze imperfekcyjne obciążenie $q_{d 2}$ (rys. 2b), które oblicza się ze wzoru:

$$
q_{d 2}(x)=16 N_{E d} \frac{e_{0}}{L^{2}}\left(6 \frac{x}{L}-6 \frac{x^{2}}{L^{2}}-1\right)
$$

Obciążenie imperfekcyjne $q_{d 2}(\mathrm{x})$ jest samozrównoważone, podobnie jak w przypadku pręta ściskanego siłą stałą na długości, gdzie obciążenie równomierne $q_{d 1, m}$ jest równoważone przez skupione siły skrajne $R_{d 1, m}$. 
a)

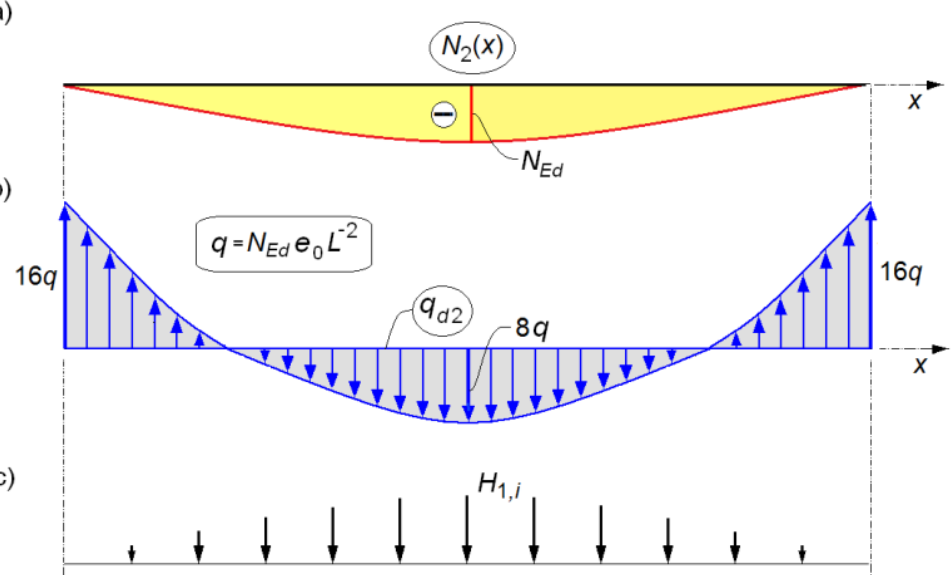

Rys. 2. a) paraboliczny rozkład siły ściskającej w stężanym elemencie, b) obciążenie imperfekcyjne $q_{d 2}$, c) siły imperfekcyjne od skręcenia kratownicy $H_{1}$

Fig. 2. a) parabolic distribution of the compression force in the restrained member, b) loadings $q_{d 2}$ from imperfections, c) imperfection loadings $H_{1}$ from of torsion

Łączne obciążenie imperfekcyjne $q_{d 2, m}$ od $m$ stężanych elementów przekazywane na stężenie (z uwzględnieniem jego odkształcenia) wyznacza się ze wzoru:

$$
q_{d 2, m}(x)=16 \sum_{j=1}^{m} N_{E d, j} \frac{e+\delta_{q 2, w}}{L^{2}}\left(6 \frac{x}{L}-6 \frac{x^{2}}{L^{2}}-1\right)
$$

gdzie: $\delta_{q 2, w}$ - ugięcie stężenia w środku rozpiętości od oddziaływań $q_{d 2}$ i wszystkich obciążeń zewnętrznych, uzyskane z analizy I rzędu (gdy w analizie ustroju stosuje się teorię II rzędu, to można przyjąć $\delta_{q 2, w}=0$ ).

Imperfekcyjne obciążenie $q_{d 2}(x)$ jest przekazywane na płatwie (powodując powstanie w nich sił podłużnych $F_{d 2}$ ) oraz na stężenie poprzeczne.

Imperfekcyjne siły podłużne w płatwiach pośrednich $F_{d 2, m, i}\left(x_{i}\right)$ oraz płatwiach okapowych $F_{d 2, m}(0)$ i $F_{d 2, m}(L)$ od $m$ stężanych elementów oblicza się ze wzorów:

$$
\begin{aligned}
& F_{d 2, m, j}\left(x_{i}\right)=\int_{x_{i}-0,5 a}^{x_{i}+0,5 a} q_{d 2}(x) d x=16 a \sum_{j=1}^{m} N_{E d, j} \frac{e+\delta_{q 2, w}}{L^{2}}\left(6 \frac{x_{i}}{L}-6 \frac{x_{i}^{2}}{L^{2}}-1-\frac{a^{2}}{2 L^{2}}\right) \\
& F_{d 2, m}(0)=F_{d 2, m}(L)=\int_{0}^{0,5 a} q_{d 2}(x) d x=4 a \sum_{j=1}^{m} N_{E d, j} \frac{e+\delta_{q 2, w}}{L^{2}}\left(3 \frac{a}{L}-\frac{a^{2}}{L^{2}}-2\right)
\end{aligned}
$$




\section{Oddziaływanie imperfekcyjne spowodowane skręceniem płaszczyzny głównej kratownicy}

W obliczaniach stężania wg [3] uwzględnia się obciążenie od łukowych wygięć stężanych elementów o strzałce $e_{0}$, występujących w płaszczyźnie połaci dachu (rys. 3a). W tym modelu analizuje się np. ściskane pasy górne, jako pojedyncze pręty „wyizolowane” z kratownicy, które nie są powiązane wykratowaniem z pasami dolnymi. Taki model obliczeniowy nie jest poprawny, gdyż nie odzwierciedla w pełni zachowania się i wytężenia konstrukcji rzeczywistej.

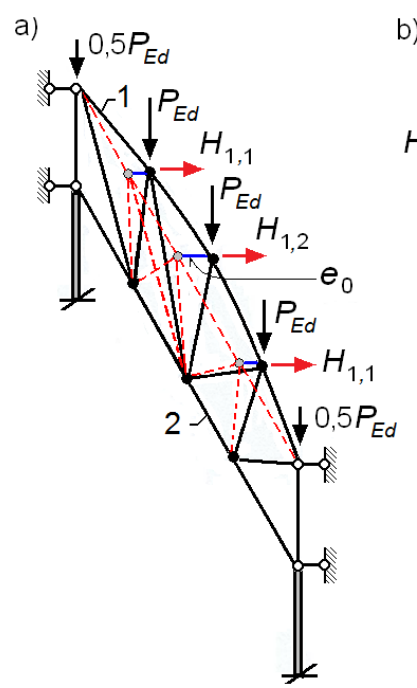

b)

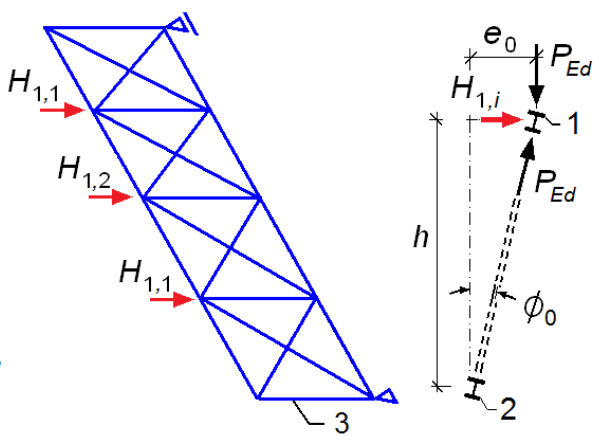

d)

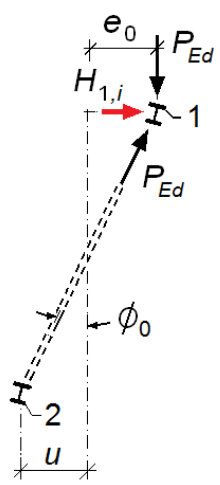

Rys. 3. Schemat: a) skręcenia płaszczyzny głównej kratownicy, b) obciążenia stężenia, c) wygięcia pasa górnego, d) znakozmiennego wygięcia pasów górnego i pasa dolnego; 1 - pas górny kratownicy, 2 - pas dolny kratownicy, 3 - stężenie

Fig. 3. Scheme of: a) torsion of the truss main plane, b) loads of bracing system, c) bow of the bottom chord, d) bow of the upper and bottom chord in different directions; 1 - truss upper chord, 2 - truss bottom chord, 3 - lateral bracing system

Ściskany pas górny kratownicy jest krzywoliniowy, rozciągany pas dolny zaś jest prostoliniowy (rys. 3a). W wyniku połączenia obu pasów wykratowaniem występuje skręcenie płaszczyzny głównej kratownicy. Stąd oprócz imperfekcji wygięcia pasa o strzałce $e_{0}$, występuje imperfekcja skręcenia o kąt $\phi_{0}(x)$ płaszczyzny głównej kratownicy (rys. 3c). W efekcie działania pionowych obciążeń $P_{E d}$ (przyłożonych w węzłach górnych) na skręconą kratownicę powstają poziome siły imperfekcyjne $H_{1, i}(x)$. Przekazują się one na płatwie oraz stężenie (rys. 3b), powodując ich dodatkowe wytężenie. Przyjmując schemat wytężenia ustroju jak na rys. 2c, imperfekcyjne poziome oddziaływania $H_{1, i}\left(x_{i}\right)$ od skręcenia kratownicy w poszczególnych jej węzłach $i$, które wyznacza się ze wzoru: 


$$
H_{1, i}(x)=\frac{y\left(x_{i}\right)}{h_{i}} P_{E d}
$$

gdzie: $h_{i}$ - wysokość konstrukcyjna kratownicy w węźle $i$.

Zakładając paraboliczne wg (6) wygięcie stężanego pasa górnego oraz jednakowe, pionowe siły węzłowe $P_{E d}$, imperfekcyjne obciążenia $H_{1, i}\left(x_{i}\right)$ od skręcenia kratownicy w poszczególnych jej węzłach $i$, wyznacza się ze wzoru:

$$
H_{1, i}\left(x_{i}\right)=4 P_{E d} e_{0} \frac{x_{i}}{h_{i} L^{2}}\left(L-x_{i}\right)
$$

Poziome obciążenia imperfekcyjne $H_{1, i, m}$ od $m$ stężanych pasów kratownic w ich węzłach $i$, wyznacza się z wzoru:

$$
H_{1, i, m}\left(x_{i}\right)=4 \sum_{j=1}^{m} P_{E d, j}\left(e+\delta_{q 2, H, w}\right) \frac{x_{i}}{h_{i} L^{2}}\left(L-x_{i}\right)
$$

gdzie: $\delta_{q 2, H, w}$ - ugięcie stężenia w środku rozpiętości od $q_{d 2}$ i $H_{1}$ oraz wszystkich obciążeń zewnętrznych (np. wiatru $W$ ), uzyskane z analizy I rzędu (gdy stosuje się teorię II rzędu, to można przyjąć $\delta_{q 2, H, w}=0$ ).

Rozkład imperfekcyjnych sił od skręcenia kratownicy $H_{1, i}\left(x_{i}\right)$ zmienia się na jej długości. W analizowanym przypadku jest on paraboliczny (rys. 2c), zgodny z przyjętym wygięciem osi stężanego elementu $y(x)$. Największe oddziaływania $H_{1, i}\left(x_{i}\right)$ są w środku rozpiętości kratownicy, gdy $y(0,5 L)=e_{0}$.

\section{Analiza oddziaływań imperfekcyjnych od wygięcia ściskanych pasów i skręcenia płaszczyzny głównej kratownicy}

Analizy numeryczne modeli 3D (wg teorii I i II rzędu) dachów kratowych ze stężeniem (o schemacie jak w przykładzie w [2]) i wariantowych ich rozwiązaniach konstrukcyjnych, potwierdziły jakościową poprawność proponowanych wzorów na obciążenia $q_{d 2}, H_{1, i}$. Ponadto wykazały one, że w wyniku skręcania kratownicy pas dolny może być też wygięty z płaszczyzny ustroju. To wygięcie pasa $u$ (rys. 3d) zależy od rozwiązań konstrukcji dachu. Powoduje ono wzrost sił imperfekcyjnych. Zagadnienie jest więc bardziej złożone i autorzy prowadzą dalsze badania w celu uściślenia modelu wyznaczania obciążeń $q_{d 2}, H_{1, i}$.

Łączne siły podłużne w płatwiach pośrednich $F_{m, i}\left(x_{i}\right)$, spowodowane obciążeniami imperfekcyjnymi $q_{d 2, m}\left(x_{i}\right)$ i $H_{1, i, m}\left(x_{i}\right)$, można wyznaczyć ze wzoru:

$$
F_{m, j}\left(x_{i}\right)=8 \sum_{j=1}^{m} \frac{e+\delta_{q 2, H, w}}{L^{2}}\left[a N_{E d, j}\left(\frac{3 x_{i}}{L}-\frac{3 x_{i}^{2}}{L^{2}}-\frac{1}{2}-\frac{a^{2}}{L^{2}}\right)+\frac{P_{E d, j} x_{i}}{2 h_{i}}\left(L-x_{i}\right)\right]
$$

a siły w płatwiach okapowych $F_{d 2, m}(0)$ i $F_{d 2, m}(L)$ oblicza się ze wzoru (10). 
Obciążenie imperfekcyjne $q_{d 1}$ wg modelu w [3], w którym przyjęto stałą na długości siłę $N_{1}(x)=$ const $\mathrm{w}$ stężanym elemencie, jest równomierne (rys. 1c). Wszystkie siły imperfekcyjne $F_{d 1, m}$ w płatwiach pośrednich są jednakowe o tym samym zwrocie, w płatwiach okapowych zaś występują duże siły $R_{d 1, m}$ (rys. 1 ).

W przypadku parabolicznej zmienności siły ściskającej w stężanym elemencie $N_{2}(x)$ (rys. 2a), rozkład obciążenia imperfekcyjnego $q_{d 2}$ (rys. 2b) jest zmienny na długości (nierównomierny), a także znakozmienny. Obciążenia $q_{d 1}(0,5 L)$ i $q_{d 2}(0,5 L)$ są takie same. Największe obciążenia $q_{d 2}$ występują w strefie przypodporowej i są o przeciwnym zwrocie niż obciążenie w strefie środkowej $q_{d 2}(0,5 L)$. Obciążenie imperfekcyjne w strefie podporowej $q_{d 2}(0)$ i $q_{d 2}(L)$ jest dwukrotnie większe od obciążeń imperfekcyjnych: $q_{d 2}(0,5 L)$ oraz $q_{d 1}$.

$\mathrm{Z}$ porównania obciążeń imperfekcyjnych $q_{d 1}$ i $q_{d 2}$ wynika, że ich różnice są zasadnicze i mają charakter nie tylko jakościowy, ale przede wszystkim ilościowy. Ma to istotne znaczenie w wytężeniu zarówno płatwi, jak i stężenia.

Obciążenie $q_{d 2}$ jest nierównomierne i wszystkie siły imperfekcyjne $F_{d 2, m, i}$ przekazywane na płatwie mają zmienne wartości na długości stężanego elementu. W przypadku obciążenia $q_{d 1}$ siły imperfekcyjne $F_{d 1, m}$ przekazywane na płatwie pośrednie mają takie same wartości. Siły w płatwiach środkowych dachu $F_{d 1, m}(0,5 L)$ i $F_{d 2, \mathrm{~m}}(0,5 L)$ są prawie takie same. W płatwiach pośrednich, z wyjątkiem strefy przyokapowej, siły $F_{d 2, m}\left(x_{i}\right)$ są mniejsze od sił $F_{d 1, m}\left(x_{i}\right)$. Największe siły $F_{d 2, m, i}$ mogą wystąpić w płatwiach przyokapowych. Są one jednak zdecydowanie mniejsze od sił $R_{d 1}$ (w płatwi okapowej). Na przykład w konstrukcji jak na rys. 1a siła $F_{d 2}\left(x_{i}=a\right)$ stanowi $20 \%$ siły $R_{d 1}$.

W celu oceny różnic obciążeń imperfekcyjnych $q_{d 1}$ oraz $q_{d 2}$ wykonano analizy wytężenia stężenia pokazanego na rys. 1a (o schemacie jak w przykładzie w [2]). Dane: $L=24,0 \mathrm{~m}, h=2,2 \mathrm{~m}, N_{E d}=163,64 \mathrm{kN}, P_{E d}=10 \mathrm{kN}$; krzyżulce stężenia są wykonane z prętów wiotkich, nieprzenoszących sił ściskających.

Obciążenie $q_{d 1}$ powoduje największe wytężenie przypodporowych krzyżulców stężenia. W przypadku obciążenia $q_{d 2}$ największe siły w krzyżulcach stężenia występują w strefie zmiany znaku obciążenia $q_{d 2}$. $Z$ analiz wynika, że dla obciążenia $q_{d 2}+H_{1}$ w krzyżulcach stężenia (z wyjątkiem podporowych) występuje wzrost sił od 25 do $100 \%$, w stosunku do sił od obciążenia $q_{d 1}$.

Obciążenie $H_{1, i}$ generuje istotny wzrost sił w płatwiach i stężeniu. W płatwi usytuowanej w środku rozpiętości dźwigara powoduje ono $100 \%$ wzrost siły w stosunku do siły od obciążenia $q_{d 2}$ i $q_{d 1}$. Siły $H_{1, i}$ wywołują w krzyżulcu przypodporowym stężenia wzrost sił o $352 \%$, w pozostałych krzyżulcach zaś do $86 \%$, w stosunku do sił od obciążenia $q_{d 2}$. Maksymalna siła w krzyżulcu stężenia od obciążenia $q_{d 2}+H_{1, i}$ jest o $144 \%$ większa od maksymalnej siły w krzyżulcu od obciążenia $q_{d 2}$. Otrzymane różnice wytężenia stężania są bardzo duże.

W podsumowaniu wykonanych analiz należy stwierdzić, iż od obciążeń imperfekcyjnych $q_{d 2}$ i $H_{1, i}$ (wyznaczonych wg zaproponowanego modelu) zarówno $\mathrm{w}$ płatwiach, jak i w stężeniu występuje istotny wzrost sił oraz odmienny ich rozkład, w stosunku do sił obliczonych wg [3]. 


\section{Uwagi i wnioski końcowe}

Wykonane analizy jednoznacznie wskazują, że model oceny obciążeń imperfekcyjnych $q_{d 1}$ oraz obliczania stężeń i płatwi wg [3] nie jest poprawny. Wynika to $\mathrm{z}$ nie uwzględnienia $\mathrm{w}$ tym modelu rzeczywistego rozkładu siły podłużnej w stężanym elemencie oraz skręcenia płaszczyzny głównej kratownicy.

W przypadku parabolicznego rozkładu siły w stężanym elemencie obciążenie imperfekcyjne $q_{d 2}$ jest nierównomierne i znakozmienne. W strefie podporowej obciążenie $q_{d 2}(0)$ i $q_{d 2}(L)$ jest dwukrotnie większa od $q_{d 1}$. Powoduje to odmienny rozkład sił w płatwiach i stężeniu w porównaniu z oceną wg [3] (ekstremalne siły mogą być większe i występują w różnych prętach).

Model wg [3] ogranicza się tylko do analizy skutków wygięcia $e_{0} \mathrm{w}$ płaszczyźnie połaci pasa i nie uwzględnia sił imperfekcyjnych $H_{1, i}$, które są generowane $\mathrm{w}$ wyniku skręcenia płaszczyzny głównej kratownicy $\mathrm{z}$ wygiętym pasem górnym. Powodują one dodatkowy, istotny wzrost wytężenia płatwi i stężenia.

Zaproponowana ocena obciążeń imperfekcyjnych $q_{d 2}$ i $H_{1, i}$ umożliwia analizę uściślonego modelu wytężenia płatwi i stężeń. Przedstawione ilościowe i jakościowe różnice proponowanych modeli obliczeniowych $\mathrm{w}$ stosunku do oceny wg [3] są bardzo duże. Dlatego należałoby rozważyć wprowadzenie odpowiednich korekt dotyczących analizowanego zagadnienia w nowelizacji [3].

\section{Literatura}

[1] Czepiżak D., Biegus A.: Refined calculation of lateral bracing systems due to global geometrical imperfections, Journal of Constructional Steel Research 119 (2016), s. 30-38.

[2] Pałkowski Sz., Piątkowski M.: O obliczaniu poprzecznych stężeń dachowych, Inżynieria i Budownictwo $\mathrm{nr}$ 4/2014, s. 210-213.

[3] PN-EN 1993-1-1:2006 Eurokod 3. Projektowanie konstrukcji stalowych. Część 1-1: Reguły ogólne i reguły dla budynków, PKN, Warszawa.

\section{A REFINED MODEL OF LOADS FROM IMPERFECTIONS ACTING ON PURLINS AND BRACINGS}

\section{S u m m a r y}

Refined modes of identification of loads from imperfections on braced free supported trusses have been presented. The loads have been determined according both their real parabolic distribution along the braced members and the torsion of the main plane of the truss. The analytic relationships for calculation of the loads from imperfections in the strain analysis of purlins and bracings have been given and obtained results have been discussed.

Keywords: loads from imperfections, truss, torsion of the truss, purlin, bracing system

Przestano do redakcji: 07.06.2016 $r$.

Przyjęto do druku: 30.06 .2016 r.

DOI: $10.7862 / \mathrm{rb} .2016 .36$ 